\title{
Otolith Loss Or Disorganization
}

National Cancer Institute

\section{Source}

National Cancer Institute. Otolith Loss Or Disorganization. NCI Thesaurus. Code

C161552.

Displacement of the otoliths within the inner ear and resulting vestibular dysfunction,

usually due to aging, labyrinthine disease or infection, or head trauma. 